\title{
Filigrane
}

Écoutes psychothérapiques

\section{Fusion mère-fille. S'en sortir ou y laisser sa peau 1, de Doris-Louise Haineault}

\section{François Gauthier}

Volume 15, numéro 2, automne 2006

URI : https://id.erudit.org/iderudit/014469ar

DOI : https://doi.org/10.7202/014469ar

Aller au sommaire du numéro

Éditeur(s)

Revue Santé mentale au Québec

ISSN

1192-1412 (imprimé)

1911-4656 (numérique)

Découvrir la revue

Citer ce compte rendu

Gauthier, F. (2006). Compte rendu de [Fusion mère-fille. S'en sortir ou y laisser sa peau 1, de Doris-Louise Haineault]. Filigrane, 15(2), 96-97.

https://doi.org/10.7202/014469ar d'utilisation que vous pouvez consulter en ligne. 


\section{Fusion mère-fille. S'en sortir ou y laisser sa peau ${ }^{1}$, de Doris-Louise Haineault}

\section{françois gauthier}

V ient d'être publié aux Presses universitaires de France un très beau texte clinique signé par Doris-Louise Haineault. Dans un langage simple, sensible et réfléchi, elle nous rend témoin du parcours analytique de trois femmes aux prises avec l'enjeu crucial du vivre/mourir au niveau psychique.

Reprenant à son compte la notion de «pacte faustien» développée par Paul Lefebvre, elle en montre les ramifications dans les dédales et subtilités des compromis négociés par la fille pour répondre et protéger sa mère de sa propre détresse tout en essayant de survivre à cette «surmère » étouffante. Cette mère, qui promet la pérennité de l'éden, trompe son enfant pour en faire sa protectrice et sa complice. La dépression passe de la mère à la fille qui devra assumer l'angoisse et l'effroi. L'enfant qui croyait s'assurer l'amour permanent d'une mère s'oblige plutôt à se développer un «faux self» pour la réparer.

Souvent l'élaboration métapsychologique proposée concernant des enjeux si complexes donnent lieu à des textes abscons, ce qui n'est pas du tout le cas ici. Il est possible de suivre facilement la pensée de l'auteur dans son exposé théorique et plus encore dans ses trois longues vignettes cliniques.

Une mère qui exige de sa fille de treize ans de lui rembourser concrètement tout ce qu'elle a dépensé d'argent pour elle depuis sa naissance... une autre qui surnomme sa fille hypothèque car elle est la concession qu'elle a dû faire à son conjoint pour qu'il l'épouse et la sorte de sa propre misère financière et sociale... Ce sont là deux exemples qui marquent le ton de l'horreur et défient l'imagination que l'analyste devra dénouer dans un travail laborieux ponctué d'embûches et de moments de découragement tant côté patiente que côté analyste.

Comme il est écrit très justement en quatrième de couverture : «ce livre [...] s'adresse à tous ceux et celles curieux de comprendre la complexité des liens qui unissent une mère à son enfant. »

françois gauthier 3 -10807, millen montréal qc h2c 2e 9 gauthierf@videotron.ca 
Fusion mère-fille. S'en sortir ou y laisser sa peau, de Doris-Louise Haineault

\section{Note}

1. Doris-Louise Haineault, Fusion mère-fille. S'en sortir ou y laisser sa peau, Paris, PUF, 2006. 